\title{
Oak Ridge National Laboratory High Performance Cast Aluminum Alloys for Next Generation Passenger Vehicle Engines
}

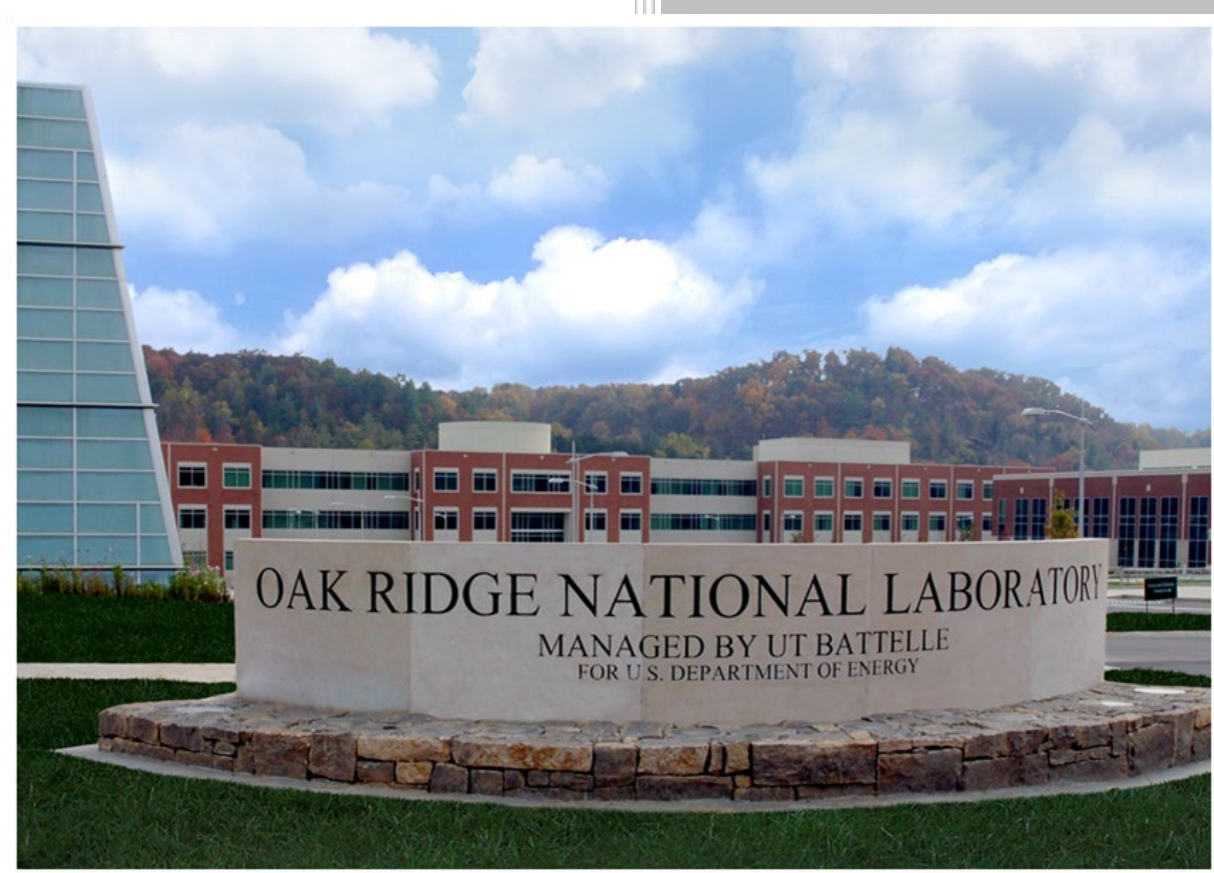

Amit Shyam and J. Allen Haynes Oak Ridge National Laboratory

Gregg Black FCA US LLC

Jose Talamantes Nemak

November 1, 2018 


\section{DOCUMENT AVAILABILITY}

Reports produced after January 1, 1996, are generally available free via US Department of Energy (DOE) SciTech Connect.

Website http://www.osti.gov/scitech/

Reports produced before January 1, 1996, may be purchased by members of the public from the following source:

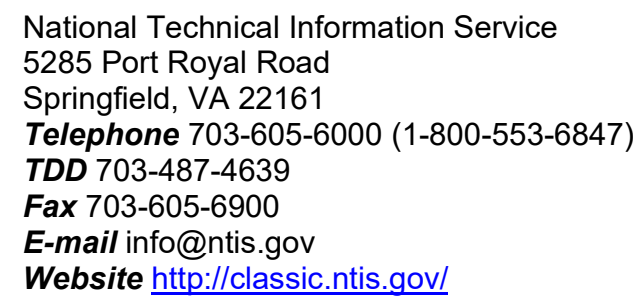

Reports are available to DOE employees, DOE contractors, Energy Technology Data Exchange representatives, and International Nuclear Information System representatives from the following source:

Office of Scientific and Technical Information

PO Box 62

Oak Ridge, TN 37831

Telephone 865-576-8401

Fax 865-576-5728

E-mail reports@osti.gov

Website http://www.osti.gov/contact.html

This report was prepared as an account of work sponsored by an agency of the United States Government. Neither the United States Government nor any agency thereof, nor any of their employees, makes any warranty, express or implied, or assumes any legal liability or responsibility for the accuracy, completeness, or usefulness of any information, apparatus, product, or process disclosed, or represents that its use would not infringe privately owned rights. Reference herein to any specific commercial product, process, or service by trade name, trademark, manufacturer, or otherwise, does not necessarily constitute or imply its endorsement, recommendation, or favoring by the United States Government or any agency thereof. The views and opinions of authors expressed herein do not necessarily state or reflect those of the United States Government or any agency thereof. 
Materials Science and Technology Division

High Performance Cast Aluminum Alloys for Next Generation Passenger Vehicle Engines

\author{
Amit Shyam and J. Allen Haynes \\ Oak Ridge National Laboratory \\ Gregg Black \\ FCA US LLC \\ Jose Talamantes \\ Nemak
}

Date Published: November 1, 2018

\author{
Prepared by \\ OAK RIDGE NATIONAL LABORATORY \\ Oak Ridge, TN 37831-6283 \\ managed by \\ UT-BATTELLE, LLC \\ for the \\ US DEPARTMENT OF ENERGY \\ under contract DE-AC05-00OR22725
}




\begin{abstract}
The purpose of this Cooperative Research and Development Agreement (CRADA) between UT-Battelle, LLC, and FCA US LLC (herein referred to individually as "FCA US") and Nemak USA, Inc., (herein referred to individually as "Nemak") was to develop higher performance cast aluminum alloy compositions that will enable higher efficiency engines for gasoline passenger on-road vehicles. The cast aluminum engine alloys that are standard across the automotive industry, such as 319 and 356 type aluminum, have now been available for several decades. The design and implementation of higher efficiency passenger automotive engines is currently limited by the absence of economical lightweight materials with improved castability, high temperature strength and fatigue performance. Integrated computational materials engineering (ICME) based iterative design and development of a new class of cast aluminum alloys referred to as $A C M Z$ alloys was performed in this CRADA project. ACMZ alloys have targeted high temperature performance characteristics compared to industry standard 319 and 356 alloys. Several versions of ACMZ alloys were successfully cast ( $>120$ in number) by Nemak into a production aluminum cylinder head design. Three of these cylinder heads were machined successfully on the baseline cylinder head production line, with no machinability issue. One such cylinder head completed a durability test schedule at FCA US. Preliminary test results suggest that the new family of cast aluminum alloys may provide opportunity for the automotive industry to increase engine and vehicle efficiency based on increased thermal efficiencies. A commercialization plan has been developed that will allow the introduction of these alloys in commercial vehicles.
\end{abstract}

\title{
1. STATEMENT OF OBJECTIVES
}

The overall project had the following two objectives:

- Develop high performance cast aluminum alloys with improved castability, high temperature strength and fatigue performance compared to industry standard A319 and A356 baseline alloys. Engine cylinder head cast with the new alloys will have a minimum of $25 \%$ strength improvement compared to those cast from the baseline alloys. The cost of engine cylinder heads manufactured in the new alloys will be less than $110 \%$ of heads manufactured in 319 or 356. Effectively, the new alloys will allow a $50^{\circ} \mathrm{C}$ increase in maximum operating temperature of cylinder heads (i.e. up to $300^{\circ} \mathrm{C}$ ).

- $\quad$ Evaluate the adequacy of existing ICME models and codes for the prediction of properties and development of cast aluminum alloys. A gap analysis report for existing ICME codes for cast aluminum alloy development was generated in the project and is discussed briefly in the present document.

\section{BENEFITS TO THE FUNDING DOE OFFICE'S MISSION}

This project was sponsored by the Propulsion Materials Program within the Vehicle Technologies office of DOE EERE. This project is among the most rapidly successful alloy development projects funded by the federal government. Higher efficiency internal combustion engine designs that have the potential to offer significant displacement of $\mathrm{CO}_{2}$ and gasoline over the next few decades, will operate at higher combustion pressures and temperatures. ACMZ alloy material is viewed as an enabler for feasibility of higher efficiency engines at FCA US (and other automotive companies). Gasoline displacement is part of the prime mission of the Vehicle Technologies office of DOE EERE. 


\section{TECHNICAL DISCUSSION OF WORK PERFORMED BY ALL PARTIES}

\subsection{FY14 effort}

Cast and heat-treated aluminum alloy materials were received at ORNL from Nemak. The following five alloys were cast and machined in the form of blocks ( $\sim 1$ " $\mathrm{x} \sim 1$ " $\mathrm{x} \sim 7$ ") from an area in a wedge casting with secondary dendrite arm spacing (SDAS) of $\sim 30 \mu \mathrm{m}$ :
- $\quad 319-\mathrm{T} 7$
- $356-\mathrm{T} 6$
- $\mathrm{A} 356-\mathrm{T} 6$
- $\mathrm{A} 356+0.5 \mathrm{Cu}-\mathrm{T} 6$

- $206-\mathrm{T} 6$

Two categories of tasks were performed in FY14 namely (i) characterization of baseline aluminum alloys and (ii) implementation of predictive ICME models for alloy development and materials property prediction. These are detailed below.

\section{Characterization of baseline alloys}

Specimens were prepared for mechanical, microstructural and thermal property characterization of these baseline alloys. The mechanical property characterization included the tensile behavior of the alloys at room and elevated temperature (up to $300^{\circ} \mathrm{C}$ ) for aged specimens. The specimens for high temperature mechanical testing had an additional preconditioning treatment performed on them which consisted of a 200 hour treatment at the testing temperature. The tensile properties of the six alloys were characterized at $20,200,250$ and $300^{\circ} \mathrm{C}$. The ultimate tensile strength (UTS) variation with temperature for the baseline $3 \mathrm{xx}$ series alloys are compared in Figure 1. The minimum target room temperature (blue) and $300^{\circ} \mathrm{C}$ (red) ultimate tensile strength for these alloys are also included in Figure 1. It is observed that several alloys met the minimum target at room temperature but none of the alloys met the minimum target at $300^{\circ} \mathrm{C}$. Development of cast aluminum alloys with the desired high temperature strength was, therefore, the most demanding challenge in the present project.

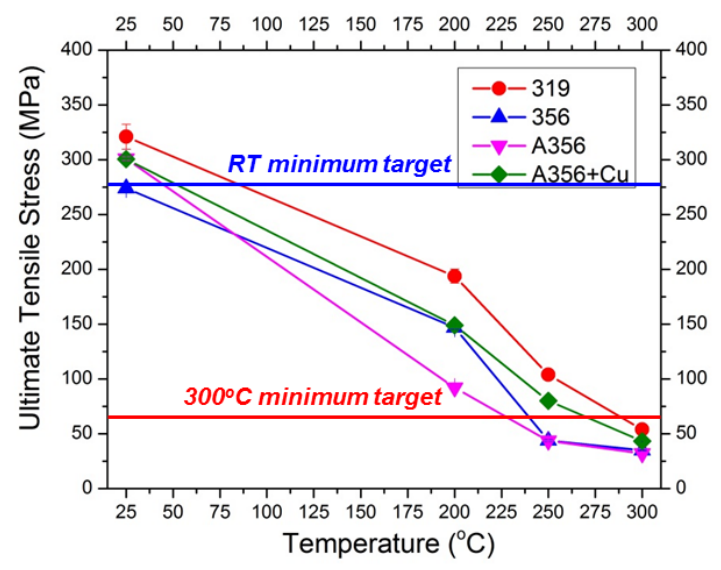

Figure 1: Ultimate tensile strength variation with temperature for baseline 3xx aluminum alloys. 

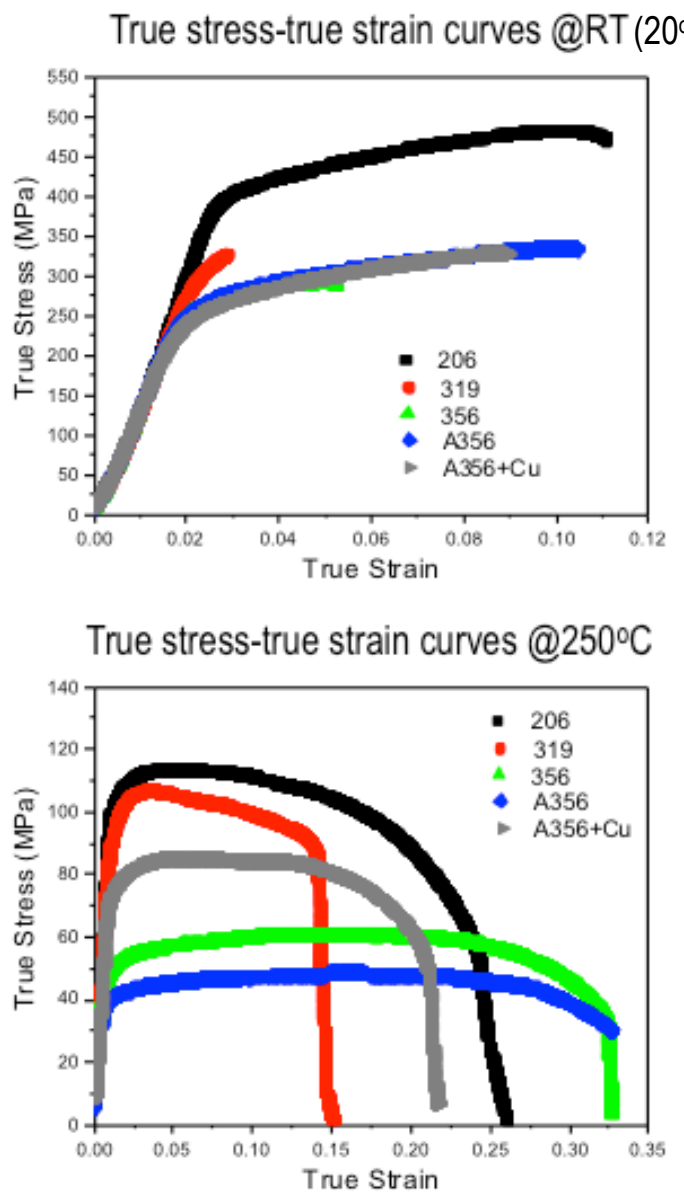

Figure 2: True stress-strain curves of the five supplied cast aluminum alloys at RT $\left(20^{\circ} \mathrm{C}\right)$ and $250^{\circ} \mathrm{C}$.

The true stress-true strain curves of the alloys at 20 and $250^{\circ} \mathrm{C}$ are compared in Figure 2. All alloys displayed a distinctive change to softening behavior at the higher temperature compared to hardening alone at room temperature. The change in hardening characteristics of all alloys was examined in detail and also related to the change in fracture surface characteristics. As shown in Figure 1, the yield and ultimate tensile strength of the alloys decreased significantly due to an increase in temperature.

The thermal conductivity of the baseline alloys was measured by measuring the thermal diffusivity, specific heat and thermal expansion of the baseline alloys. Thermal conductivity is the product of thermal diffusivity (measured by the laser flash technique), specific heat and density of the material. In order to measure the density at elevated temperature, the thermal expansion needs to be measured. High thermal conductivity is an important requirement of engine cylinder head applications. The effect of temperature on the thermal conductivity of baseline 3xx series aluminum alloys is shown in Figure 3. It is observed that the 319 alloy has a lower thermal conductivity than 356 type alloys at all temperatures. 


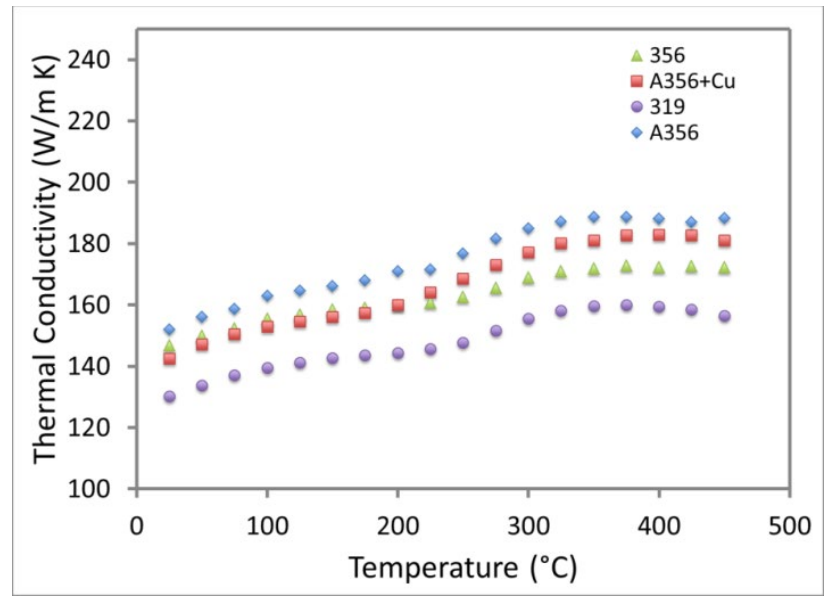

Figure 3: Thermal conductivity of baseline $3 \mathrm{xx}$ series aluminum alloys up to $450^{\circ} \mathrm{C}$.

Detailed microstructural characterization was performed on the received alloys. An example of the type of microstructural characterization (optical and energy dispersive spectroscopy (EDS) in a scanning electron microscope (SEM)) on 319 aluminum alloy is shown in Figure 4. Figure 4a includes the backscattered SEM image along with the color coded elemental image maps for two different regions in this alloy. Presence of various intermetallic precipitates that are key to the castability and fatigue characteristics of the material is noted in Figure 4a. EDS analysis along with a literature review revealed the composition of the large scale precipitates present in 319 aluminum (Figures $4 \mathrm{a}$ and $\mathrm{b}$ ). In addition, the SEM image in Figure $4 \mathrm{~b}$ reveals the other microstructural features associated with 319 cast aluminum alloys including SDAS, microporosity, the eutectic silicon and larger $\beta-\mathrm{Al}_{5} \mathrm{FeSi}$ type precipitates (with or without Mn which determines their morphology). The porosity distribution and in particular the largest pores in the distribution are responsible for initiation of fatigue cracks in the microstructure of 319 alloy being investigated. The objective of the microstructural characterization was to establish microstructureproperty relationships for the received alloys (in the as-aged condition).

(a)

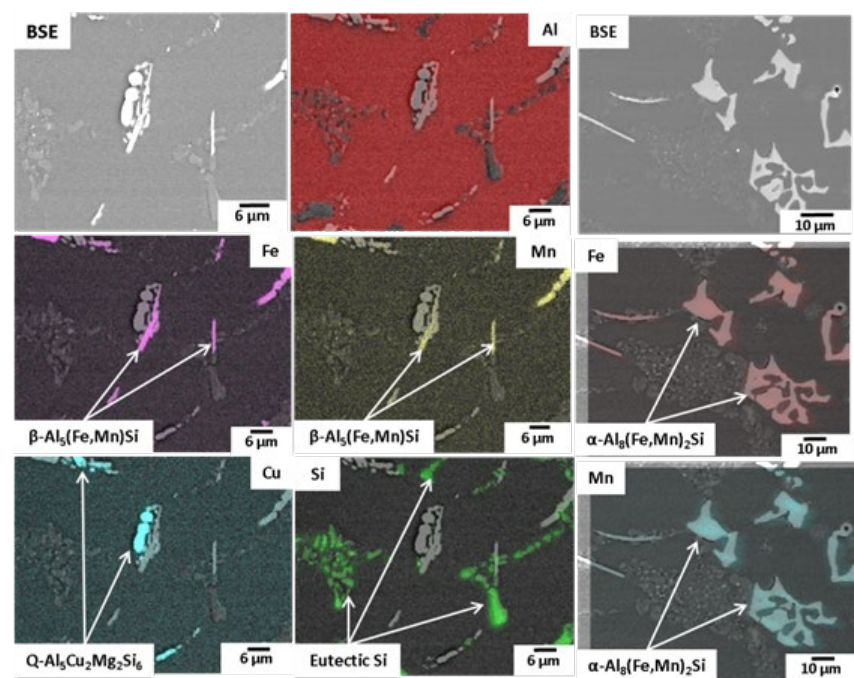

(b)

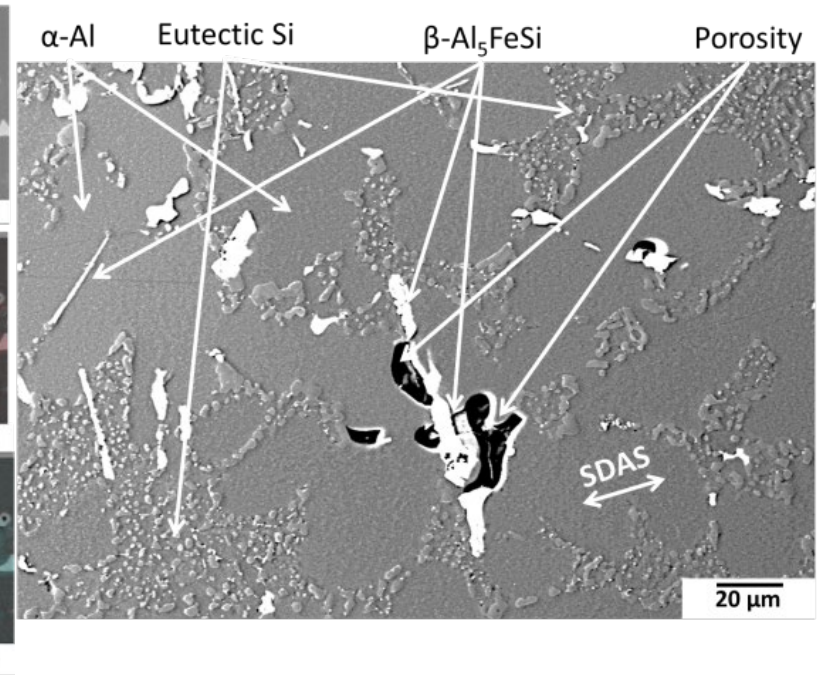




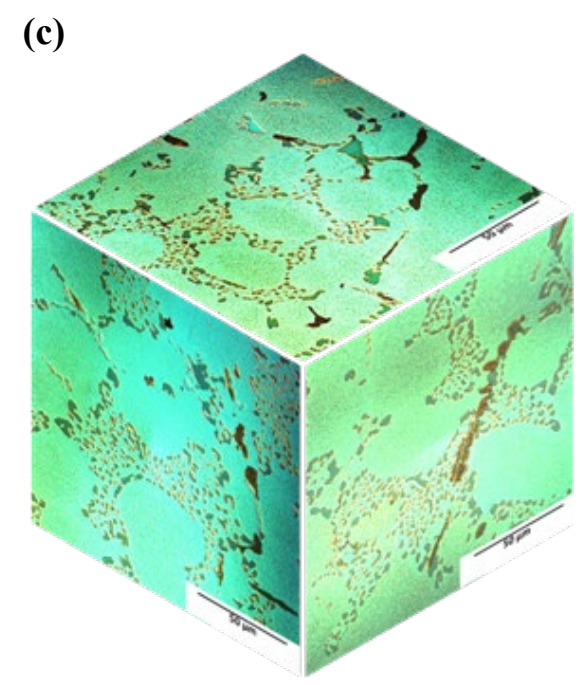

Figure 4: Example of microstructure characterization for 319-T7 cast aluminum (see text for details).

(a)

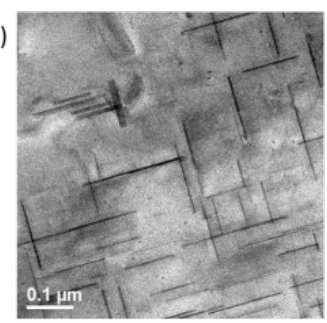

(b)

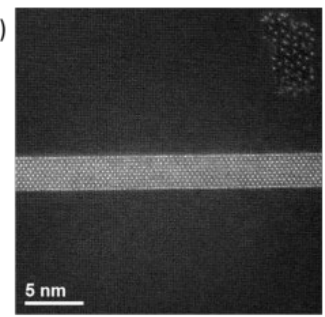

(e)

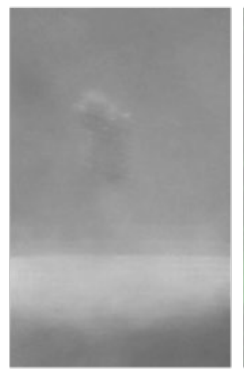

(c)

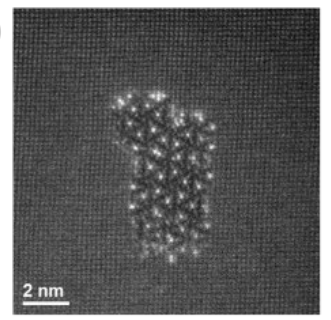

(d)
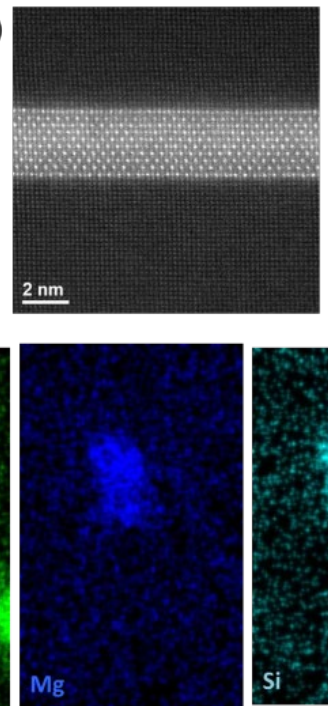

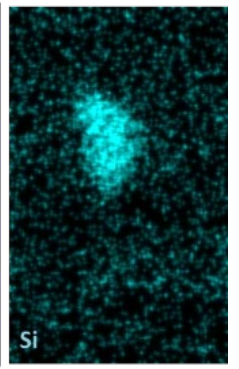

Figure 5: HRTEM images of 319-T7 alloy. (a) Bright field image of nanoscale strengthening precipitates. (b) Dark field image of two different types of nanoscale precipitates in 319-T7 with an irregular shape shown magnified in (c) and a plate shape shown in (d). 5(e) shows the chemical analysis in TEM EDS mode for these same two precipitates. 
A summary of high resolution TEM images for 319-T7 aluminum as observed in aberration corrected transmission electron microscopy is shown in Figure 5. A bright field image that shows the fine distribution of Al-Cu type precipitates is shown in Figure 5(a). These precipitates appear dark in the bright field image. A single plate like precipitate appears bright in the dark field image in the $<001>$ zone axis shown in Figure 5(b). The plate like precipitate appears in the middle of the image in Figure 5(b) whereas another fine precipitate is in the top right of this image. The latter precipitate is not coherent with the matrix and a further magnified image of this precipitate with atomic columns resolved is shown in Figure 5(c). A heavy atomic number element (likely copper) decorates this precipitate in a hexagonal pattern. The plate like precipitate was also observed at a higher magnification and is shown in Figure 5(d). This precipitate was observed to remain relatively coherent with the $\alpha$-aluminum matrix. Energy dispersive spectroscopic (EDS) chemical analysis in a TEM (Figure 5(e)) reveals that the plate like precipitate is $\mathrm{Al}-\mathrm{Cu}$ type and the lattice spacing indicates that it is likely the $\theta^{\prime}\left(\mathrm{Al}_{2} \mathrm{Cu}\right)$ phase with detectable amounts of $\mathrm{Si}$ and $\mathrm{Mg}$. The precipitate in Figure 5(c) was revealed to be a Al-Cu-Mg-Si type precipitate by TEM-EDS analysis and is likely the well reported Q phase (also observed at a microscopic scale in Figure 4(a)). The above analysis provided access to the details of the structure and chemistry of the nanoscale strengthening precipitates in the $3 \mathrm{xx}$ series of aluminum alloys. Similar analysis was performed in 2xx series aluminum alloys and is reported in Section 3.2.

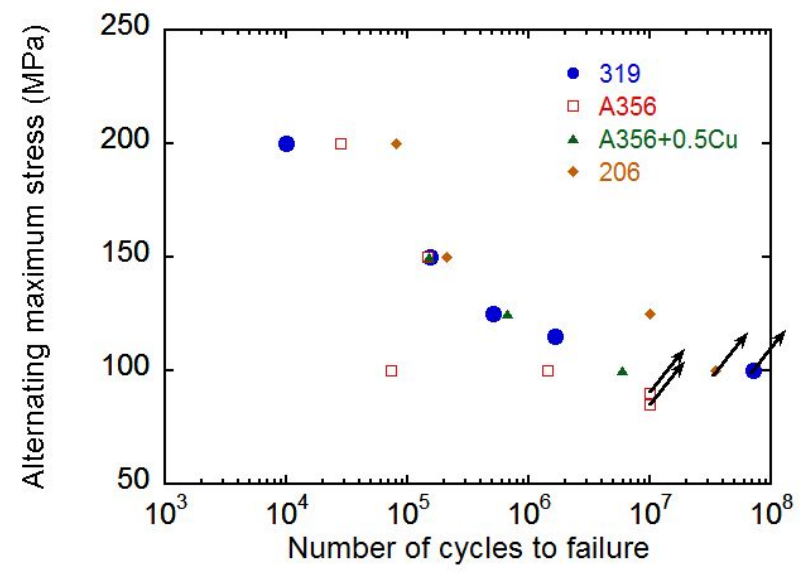

Figure 6: High cycle fatigue behavior of baseline cast aluminum alloys at room temperature.

High cycle fatigue testing was performed on the baseline alloys. A comparison of the high cycle fatigue behavior of three $3 \times x$ series and 206 cast aluminum alloys and is shown in Figure 6. The 3xx series alloys materials show a fatigue limit in the range 85-100 MPa which is consistent with the values reported in the literature. The 206 alloy displayed a higher fatigue limit in the range 100-120 MPa consistent with its higher strength at room temperature.

The baseline alloy characterization led to the following important conclusion about the studied alloys: the most important attribute of the aluminum alloys for use at elevated temperature is their microstructural stability at temperatures above $200^{\circ} \mathrm{C}$. To study this, the effect of preconditioning treatment temperature on the room temperature Vickers hardness value of the alloys was investigated as shown in Figure 7. It is observed that the hardness value decreases by a significant amount as a result of $300^{\circ} \mathrm{C}$ preconditioning treatment. Microstructural observations confirmed that this decrease could be largely attributed to the coarsening of the strengthening precipitates at $300^{\circ} \mathrm{C}$ (fine light colored precipitates in Figure 7 for 319 alloy). The same precipitates are fine enough to not be observed in a scanning electron microscope in the as-aged condition and were therefore characterized by high resolution transmission electron microscopy (Figure 5). 


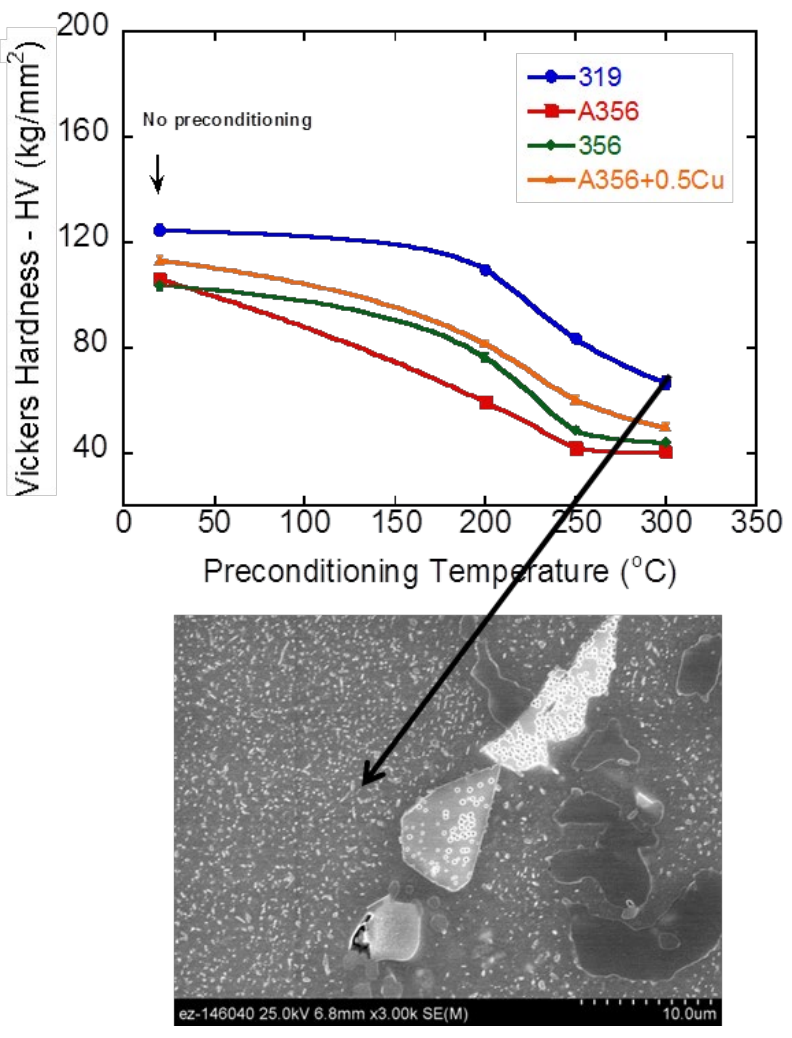

Figure 7: Effect of preconditioning (200 hour treatment) temperature on the room temperature Vickers hardness of $3 \mathrm{xx}$ series alloys. The SEM image on the right corresponds to a 319-T7 specimen preconditioned at $300^{\circ} \mathrm{C}$.

\section{Predictive models for property prediction}

As noted earlier, one of the objectives of this project was to evaluate the adequacy of ICME models towards alloy development and materials property prediction. Models and tools were evaluated for predictive capabilities and ability to bridge scales. The latter is important since for the ICME evaluations, key microstructural scales need to be defined for prediction of different properties. For example, for the fatigue limit prediction, the key microstructural scale is the mesoscale where the largest pores form and initiate cracks during cyclic loading.

A probabilistic model for the prediction of fatigue limit in 319 aluminum alloys was implemented in this project in the FY14 reporting period. This model is presented as an example of the ICME modeling for properties undertaken in the present project and is summarized below.

We produced a weakest link prediction of fatigue strength based upon the distribution of pore size and location. We adopt the framework previously implemented by Zhu et al. [Metallurgical and Materials Transactions A, May 2007, Volume 38, Issue 5, pp 1111-1122]. First, we generated a log-normal distribution of pore sizes in a gage volume that corresponded to a typical fatigue specimen, with a uniformly random distribution of pore locations within a volume. The result of this procedure is illustrated in Figure 8. A virtual fatigue staircase testing procedure was applied on this gage volume and based on a failure/runout result, the procedure was repeated 1900 times with a new microstructure corresponding to each simulated fatigue test. 
(a)

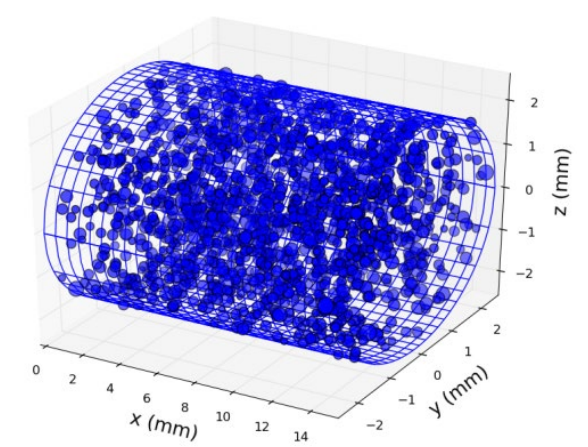

(b)

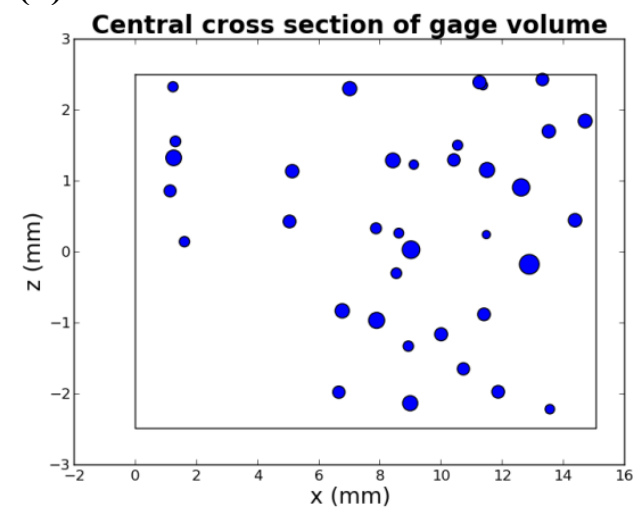

Figure 8. (a) Lognormal porosity distribution simulated in a gage volume of a fatigue specimen and (b) shows a central cross-section of the gage volume in (a). The size of the pore diameters have been magnified 1000x for visualization.

The results of the Monte Carlo simulation are now discussed. The experimentally measured mean fatigue strength and standard deviation is measured to be $\sigma_{0}=85 \pm 8.5 \mathrm{MPa}$ [Zhu et al. 2007]. For the simulation parameters applied, the developed model predicted a mean fatigue strength of $\sigma_{0}=$ $83 \pm 8.9 \mathrm{MPa}$. This result is statistically close to the experimental results. The initiating pore size is also very similar to the experimentally observed initiating pore size as seen in Figure 9. Increasing the number of samples from 1900 to 19000 in the Monte Carlo simulation resulted in the same distribution of initiating pore sizes and fatigue strength measure, leading us to believe that convergence has been adequately achieved in this simulation.

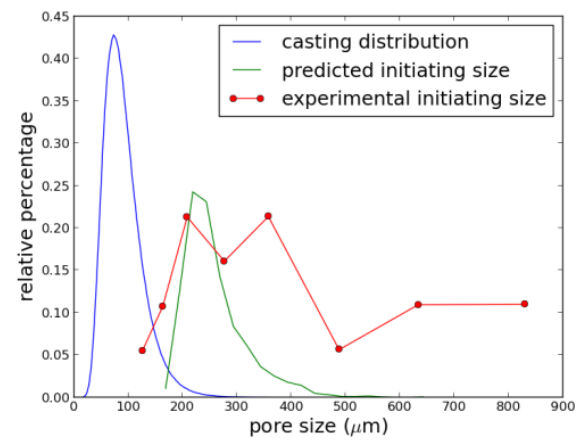

Figure 9: Input pore distribution in blue along with the pore sizes predicted to initiate failure in green and the experimentally observed initiating pore size in red marked at data points with circles. The predicted and measured initiating size distributions coincide with reasonable accuracy. 
The significance of this method is in the predictive capability for the mean fatigue strength and initiating pore sizes. Looked another way, this method allows us to computationally perform a large number of fatigue tests if the pore size distribution of a new alloy is known. Such large experimental test schedules will be prohibitively expensive and time consuming.

The limiting factor to this method is the quantification of the pore size distribution. To date, it is computationally difficult to predict the pore size distribution within a given casting system. The process is also quite difficult experimentally and requires assumptions to scale the $2 \mathrm{D}$ cross-sections into a $3 \mathrm{D}$ volume or a tedious experiment to perform a full 3D reconstruction of a representative microstructural volume.

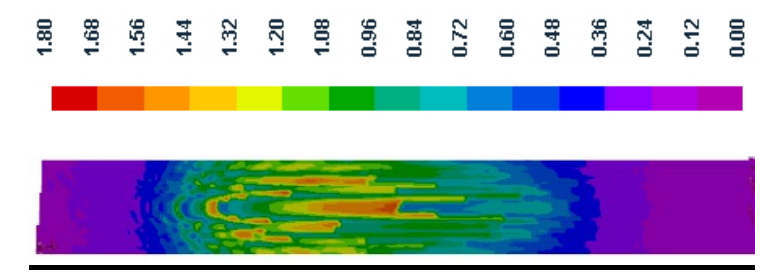

Figure 10. Microporosity prediction results for a plate casting of 319 alloy.

Progress was made towards implementation of a predictive model for pore-size distributions. Numerical simulation results were performed for the section of a plate casting with cast iron chills. The plate dimensions were $14 \times 22.9 \times 3.2 \mathrm{~cm}$. ProCAST software was used in this study for metal casting simulations. The results for microporosity distribution for 319 alloy is summarized in Figure 10. For the 319 alloy, with initial hydrogen content of $0.1 \mathrm{cc} / 100 \mathrm{~g}$, the length of the high-porosity region and the maximum microporosity value were found to be the largest compared to other $3 \mathrm{xx}$ alloys (simulations not shown). This is expected since shrinkage demand in the last stages of solidification is highest for 319 . The calculated high-porosity region for the 319 alloy can be seen in Figure 10.

\subsection{FY15 EFFORT}

It was observed in the course of the present project (for example, see Figure 7) that the high temperature performance of aluminum alloys is limited by the stability of their microstructure at elevated temperature.

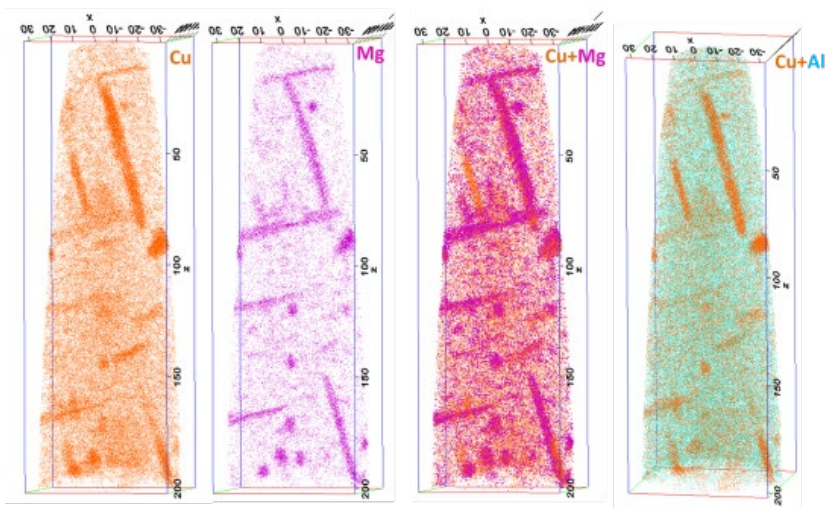

Figure 11: Atom probe tomography (APT) images for the most common elements in a 206-T6 alloy. 
For example, the 206-T6 alloy (precipitate distribution illustrated in APT chemical images shown in Figure 11) has exceptional room temperature peak hardness values and this corresponds to attractive tensile properties at lower temperature as well. At elevated temperature, however, the microstructure of this alloy can become unstable. Analysis of precipitate complexes that lead to elevated temperature instability is shown in Figure 12. The high resolution transmission electron micrograph (HRTEM) shows the so-called Q phase (Al-Cu-Mg-Si) that provides a heterogeneous nucleation site for multiple GPII zones. The GPII zones in different habit planes maintain an orthogonal relationship with each other. A similar Q-phase precipitate with two GPII precipitates around it is shown in the APT analyzed image on the right in Figure 12. In this APT image, $\mathrm{Si}$ atoms are green, $\mathrm{Mg}$ atoms are magenta and $\mathrm{Cu}$ atoms are orange. Since Mg has a much higher diffusion coefficient compared to aluminum, it is not surprising then to see the Q-phase promoting the coarsening of these precipitates at elevated temperature.
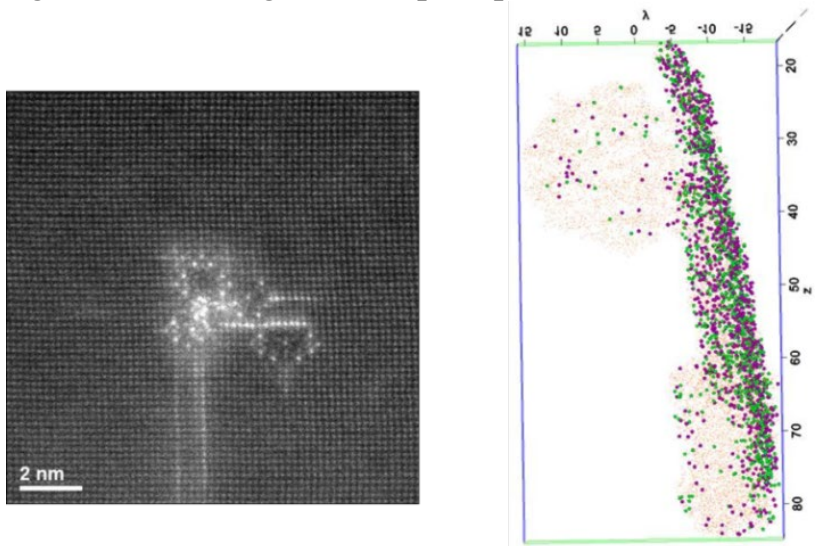

Figure 12: HRTEM image (left) and APT image (right) of a Q-phase precipitate that helps nucleate and then coarsen the Al-Cu type precipitates. Color code for the APT image: Green - Si, Magenta - Mg and Orange - $\mathrm{Cu}$.

As stated earlier, coarsening resistance is an important characteristic of higher temperature capable cast aluminum alloy. The evolution of the 206-T6 alloy microstructure was well-characterized by transmission electron microscopy (TEM), atom probe analysis and X-ray synchrotron diffraction. The 206 alloy shown in Figures 11-12 has a fine distribution of precipitates that allow the system to coarsen and lower their excess interfacial free energy. The evolution of the microstructure and mechanical properties of the 206-T6 alloy at the ageing temperature of $190^{\circ} \mathrm{C}$ is shown in Figure 13.

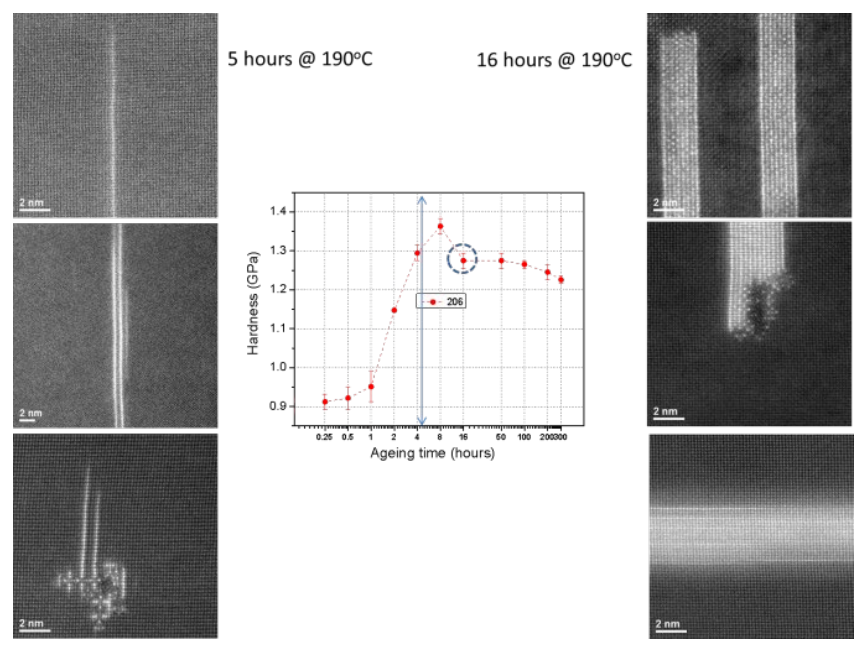

Figure 13: Effect of aging time on the microstructural stability and mechanical properties for a 206-T6 alloy. 
After 5 hour aging at $190^{\circ} \mathrm{C}$, the strengthening precipitates consisted of GP I or GP II (two layers of $\mathrm{Cu}$ atoms sandwiching three layers of aluminum atoms) zones as shown in HRTEM images on the left in Figures 12 and 13. These fine strengthening features lead to the exceptional peak strengths at room temperature. The same grain in the same alloy has been imaged after 16 hours of treatment at the aging temperature in the images on the right. It can be observed that the strengthening precipitates have coarsened to form the $\theta^{\prime}$ precipitates with a corresponding lower hardness as shown in Figure 13.

Figure 14 shows further evolution in the microstructure of the 206-T6 alloy after prolonged preconditioning at $300^{\circ} \mathrm{C}$ by HRTEM. As can be seen, the initial fine transition phases (Figure 14b) have coarsened to the $\theta^{\prime}$ phase after prolonged exposure at $300^{\circ} \mathrm{C}$ (Figure $4 \mathrm{a}$ ). The equilibrium $\theta$ phase also formed at $300^{\circ} \mathrm{C}$ and this coarsening behavior leads to decrease in mechanical properties.

(a)

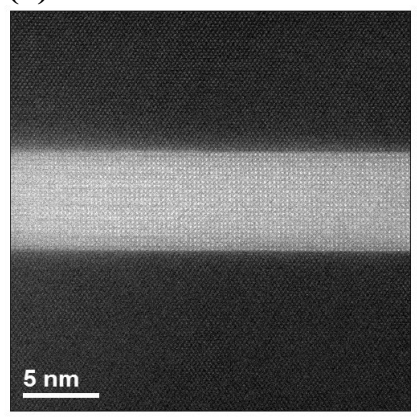

(b)

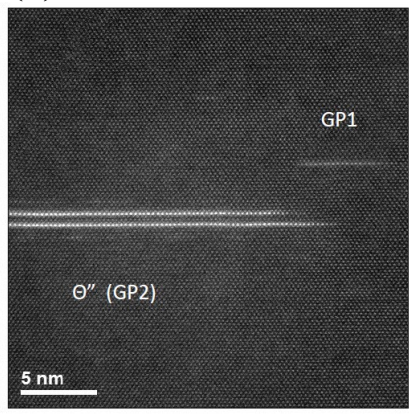

Figure 14: Evolution of the nanostructure in alloy 206-T6 after (a) 200 hours at $300^{\circ} \mathrm{C}$ and (b) ageing treatment.

In the present project, our team developed higher temperature capable aluminum alloys that have stable microstructures. We cast a number of new alloy compositions (Figure 15) in our alloy development effort.

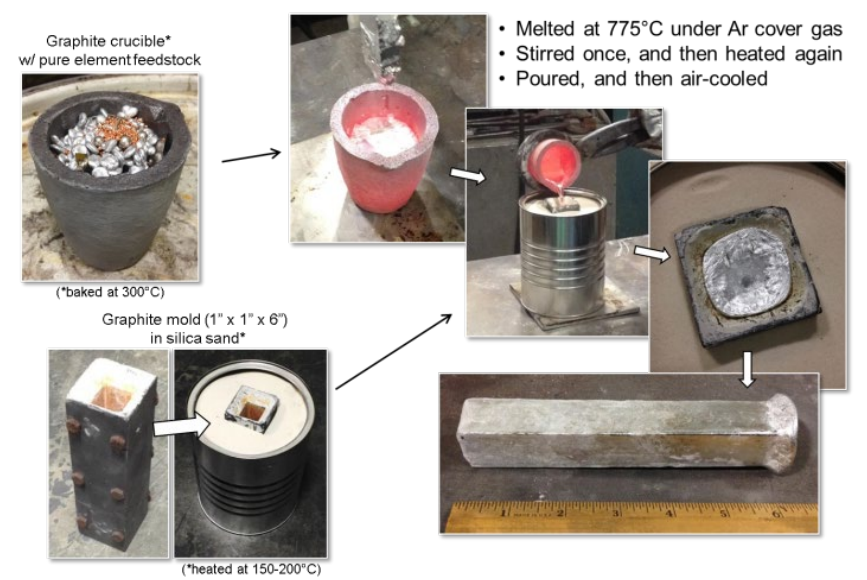

Figure 15: Summary of the alloy casting effort that was initiated at ORNL in FY2015.

An important aspect that determines the performance of materials for the cylinder head application is the thermomechanical fatigue behavior. The low cycle fatigue behavior of five candidate aluminum alloys was evaluated at 200 and $300^{\circ} \mathrm{C}$. It is noted that the specimens were provided by Nemak, the testing was performed by Element in Wixom, Michigan and the analysis was performed at FCA US highlighting the collaborative nature of the work being performed in this project. All the specimens were preconditioned at the test temperature prior to testing. The stable (half-life) hysteresis 
loops for various strain-ranges for both the 206-T6 and 319-T7 alloys at $300^{\circ} \mathrm{C}$ are compared in Figure 16. It is important to note that $300^{\circ} \mathrm{C}$ data on low cycle fatigue is rare in the literature.

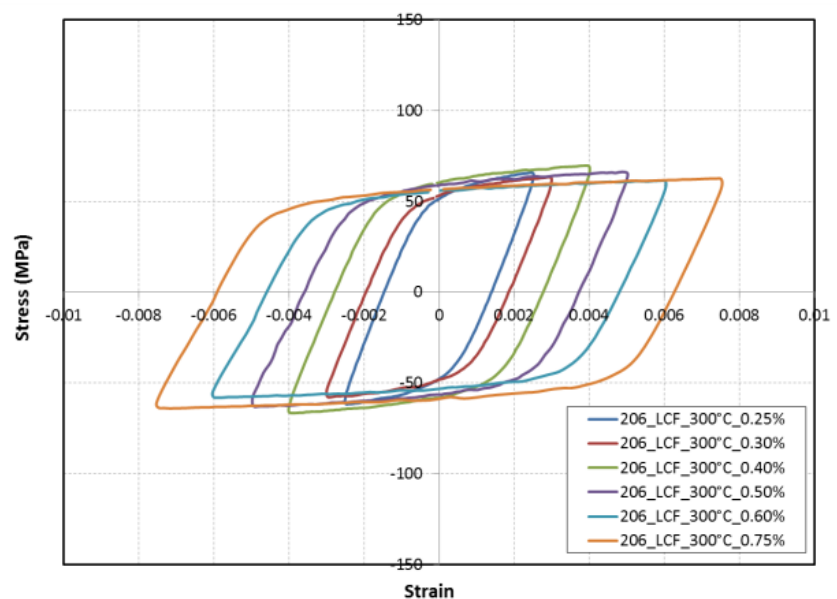

(a)

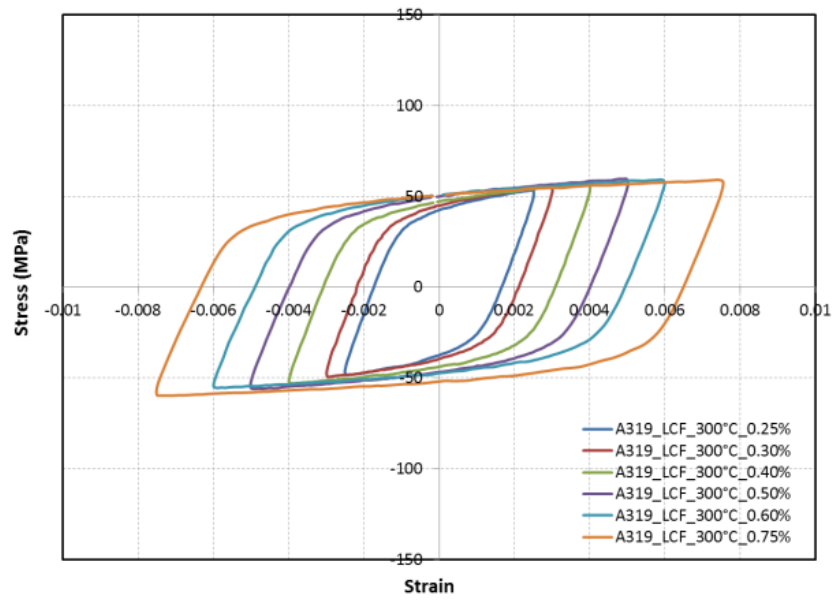

(b)

Figure 16: Stable hysteresis loops of two cast aluminum alloys at $300^{\circ} \mathrm{C}$ (a) $206-\mathrm{T} 6$ and (b) $319-\mathrm{T} 7$.

The "width" of the loop in Figure 16 is determined by the maximum and minimum strains imposed in the low cycle fatigue test. Six different tests corresponding to six different maximum strains are reported in Figure 16. It is noted that the maximum stress in the stable hysteresis loop for the 206 alloy is higher compared to the 319 alloy corresponding to the higher copper content and $300^{\circ} \mathrm{C}$ strength in the former alloy. The data generated in the initial testing program corresponded to the baseline data that was used to compare with the behavior of the new alloys that were developed in this program.

Another aspect that determines the performance of materials for the cylinder head application is the high cycle fatigue behavior. In Section 3.1, we outlined how the endurance limit can be predicted by combining the pore size distributions with the fatigue crack propagation characteristic. In that regard, a new setup to measure the small crack propagation behavior of aluminum alloys up to elevated temperature was developed. Initial comparative small crack propagation curves for 206-T6 and 319-T7 (both preconditioned at $300^{\circ} \mathrm{C}$ for 200 hours prior to testing) are presented in Figure 17. It can be observed that consistent with strength measurements reported earlier and LCF results reported above, at $300^{\circ} \mathrm{C}$, the 206 alloy has improved small crack growth rates compared to the 319 alloy. 


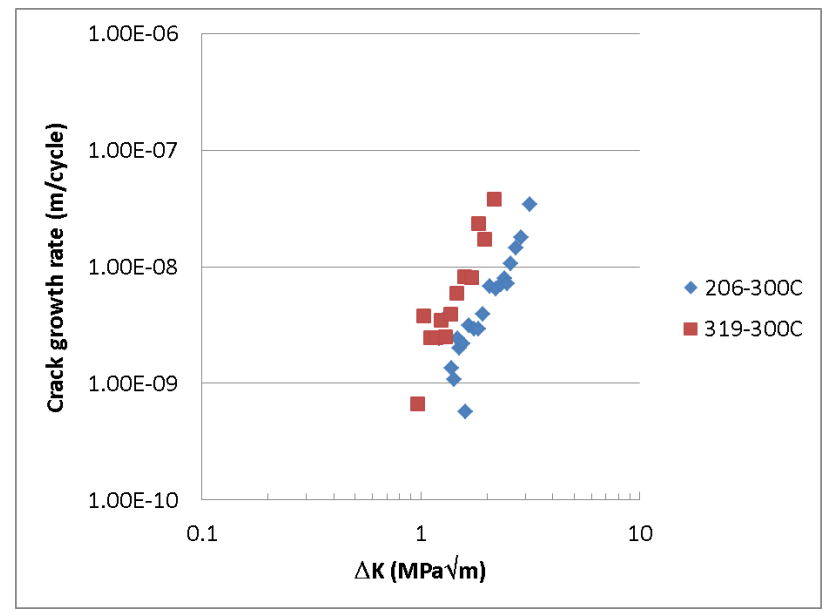

Figure 17: Small fatigue crack growth behavior of 206-T6 and 319-T7 alloys at $300^{\circ} \mathrm{C}$. Specimens were preconditioned for 200 hours at $300^{\circ} \mathrm{C}$ prior to testing.

\subsection{FY16 EFFORT}

The alloy development effort culminated this fiscal year with the filing of a joint patent from our CRADA team for a family of aluminum alloys with exceptional elevated temperature mechanical properties (see Section 4 for all subject inventions). The key alloy design concept that was implemented consisted of the knowledgebase about the propensity of certain elements to segregate to high energy interfaces of strengthening precipitates and stabilizing these interfaces (and precipitates) to higher homologous temperatures than was previously considered possible. One of the alloys in the new family of alloys, for example, had a room temperature yield and ultimate tensile strength (UTS) of 200 and $356 \mathrm{MPa}$, respectively. These compare well to the target yield and UTS properties at room temperature of 205 and $275 \mathrm{MPa}$, respectively. At $300^{\circ} \mathrm{C}$, this same alloy had an yield and ultimate tensile strength (UTS) of 105 and $137 \mathrm{MPa}$, respectively. These mechanical properties were $>2 \mathrm{X}$ the target yield and UTS properties at $300^{\circ} \mathrm{C}$ of 45 and $65 \mathrm{MPa}$, respectively. The new families of alloys, moreover, possess outstanding creep resistance up to a temperature of $350^{\circ} \mathrm{C}$.

Hot tearing resistance of the alloys needs to be acceptable for a complex casting such as a cylinder head. In that regard, a multi-institution alloy development plan to improve the hot tear resistance of alloys with elevated temperature stable microstructure was launched in FY16. An image of a hot tear casting from Nemak is shown in Figure 18.

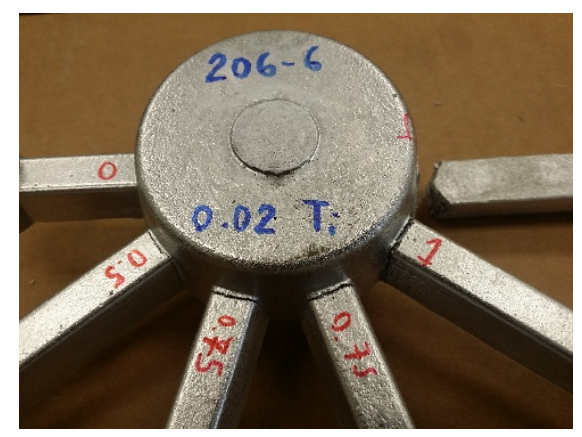

Figure 18: Image of the casting for evaluation of susceptibility to hot tearing. 
For a quantitative comparison of the hot tearing susceptibility, several castings were performed in the shape shown in Figure 18. Each casting was examined and given a hot cracking rating number. This numerical rating value was obtained by examining each arm, and assigning a value between 0 and 1 according to the following scheme:

- 1 point for a fully broken arm

- 0.75 points for a severe crack (arm fully cracked but still strongly attached to the central section)

- 0.5 points for a visible crack (arm not fully cracked)

- $\quad 0.25$ points for a crack detectable only under magnifying glass

- points when no cracks were present

The average hot tear resistance was measured for the baseline and newly developed alloys. We also performed some quantitative hot tear tests at Worcester Polytechnic Institute (WPI). Models for hot tear resistance of cast aluminum alloys were implemented and compared to experimental casting results for the same compositions that were performed at WPI. The WPI casting experimental results along with the model predictions for baseline and high temperature (HTA) alloys are shown in Figure 19. Images of hot tear experimental castings of high temperature alloys that show superior hot tear resistance are shown in Figure 20. Our CRADA team submitted another patent application summarizing the improved mechanical and casting properties of the new alloys.

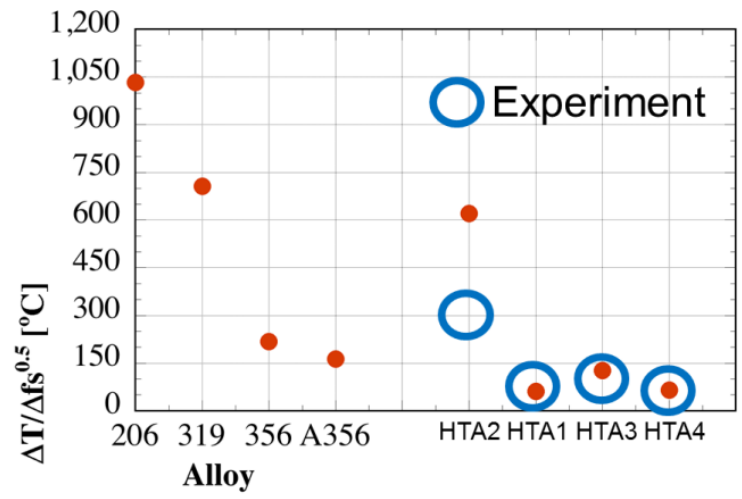

Figure 19: Model predictions and experimental hot tear resistance results for baseline and high temperature alloys (HTAs).
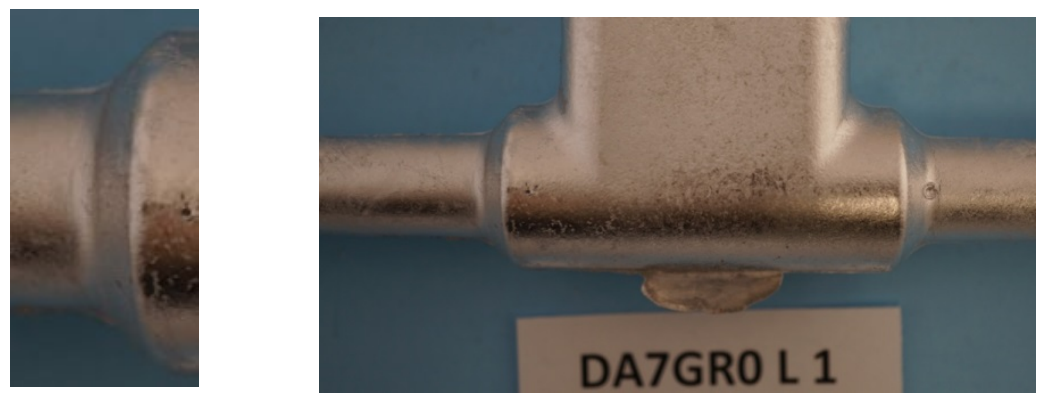

Figure 20: Images of hot tear castings that were performed at WPI. 
Much of the effort in the FY16 included selection of an optimal alloy composition that allowed good mechanical properties (microstructural stability), hot tearing resistance and low cost. The effect of grain refinement level on select alloys with good hot cracking resistance is shown in Figure 21.

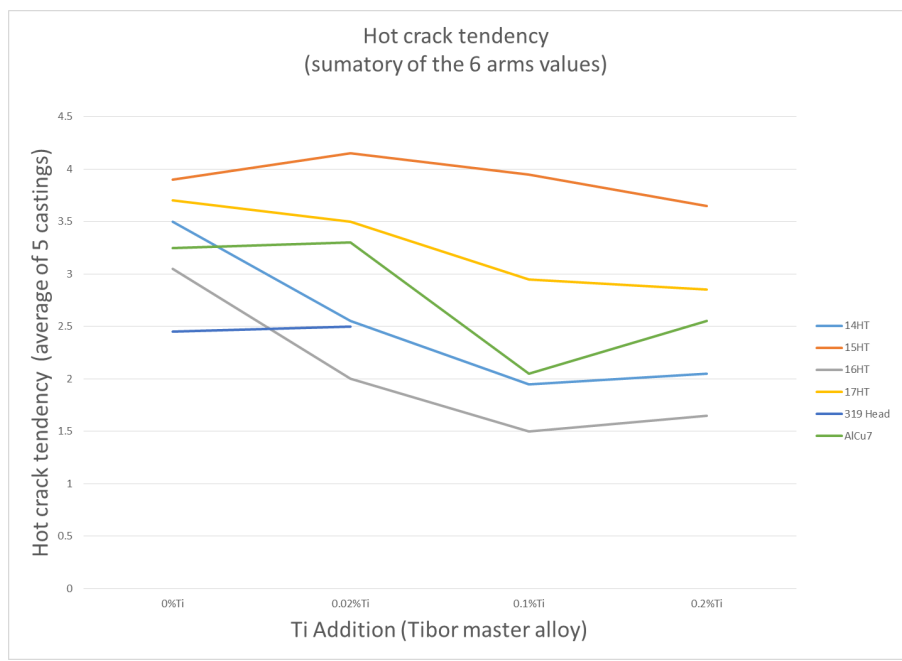

Figure 21: Hot cracking tendency for selected high temperature cast aluminum alloy compositions as a function of grain refiner addition.

A highlight of our project this FY was successful casting of automotive cylinder heads, with select compositions developed in the current effort (Figure 22), in the current FCA US baseline production tooling at Nemak. There were no chemistry related defects in the cylinder heads in the initial quality inspections performed by Nemak. Further work on characterizing the cylinder heads, developing appropriate heat treatments and characterization of residual stress, machinability and corrosion resistance continued in FY17.

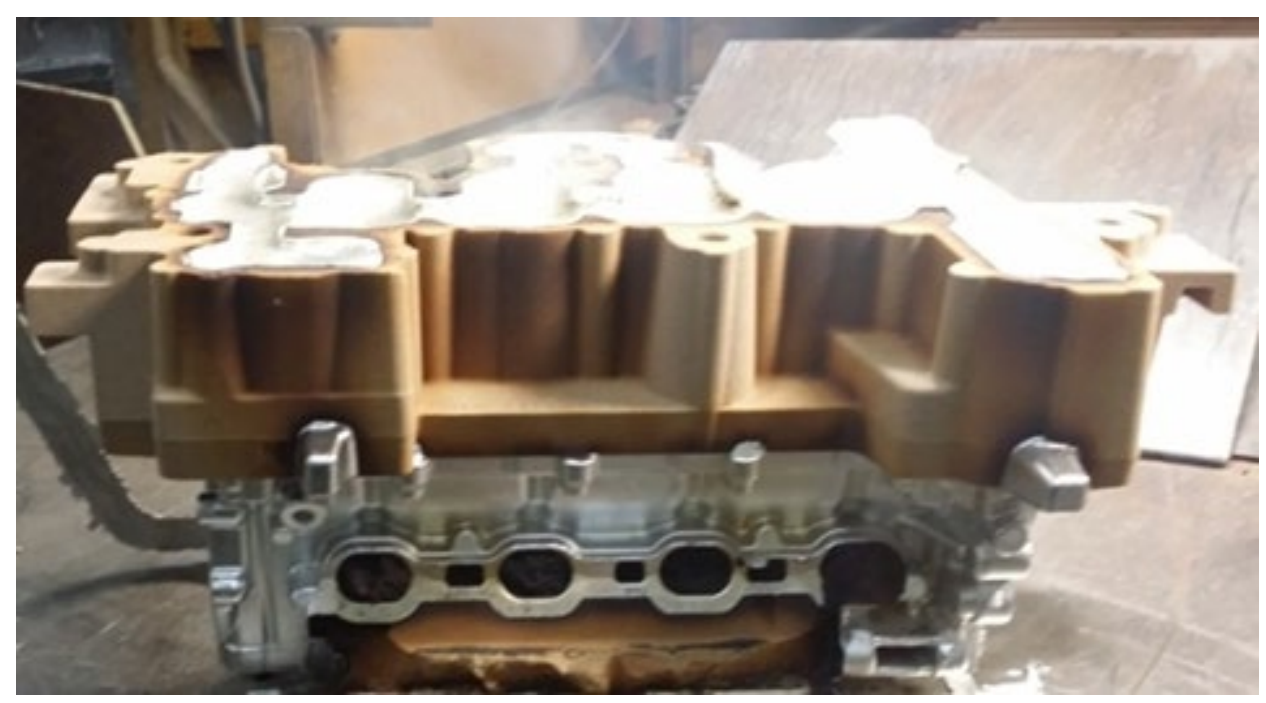

Figure 22: Cylinder head castings with one of the advanced alloy compositions. 


\subsection{FY17 WORKSCOPE AND SUMMARY}

The major goal of this project was to develop and implement cost-effective and improved cast aluminum alloys that will enable the design of higher efficiency light-duty passenger vehicle engines. The developed alloys needed to have improved high temperature strength, fatigue performance and castability compared to industry standard 319 and 356 alloys. A traditional physical metallurgy based approach, as well as computational materials science-based approach was taken to identify promising new candidate alloying elements that could be added to improve the castability and elevated temperature microstructural stability/mechanical properties of aluminum alloys. The additional or substitutional elements needed to lead to an alloy within acceptable cost constraints as stated earlier. Models for metal casting, microstructure evolution, residual stress and mechanical property prediction were implemented. Several identified alloys were cast in small batches and standard test specimens were harvested from the batch castings for property measurements. The differences in the measured and predicted properties served as a basis to identify the gaps in existing ICME codes. The gap analysis report will include the following (a) list of predictive modeling tools and grade them in terms of investment needs (short and long term), (b) list tools that can be led by industry and (c) list tools in terms of their impact.

Significant progress was achieved in the development of alloys with improved tensile properties up to $300^{\circ} \mathrm{C}$. It was demonstrated in the present project that the high temperature performance of aluminum alloys is limited by the stability of their microstructure at elevated temperature. The new alloys have stable microstructures up to a temperature of $350^{\circ} \mathrm{C}$ and three joint patent applications from our team describe the composition and process parameter range of these new alloys. In FY17, our work focused on engine testing of components cast with one of our alloys and a cost model for the new alloy family, development of a commercialization plan and a gap analysis report.

Complex cylinder heads were cast with our new ACMZ alloys (Figure 23 is an example with $8 \mathrm{wt} \% \mathrm{Cu}$ ).

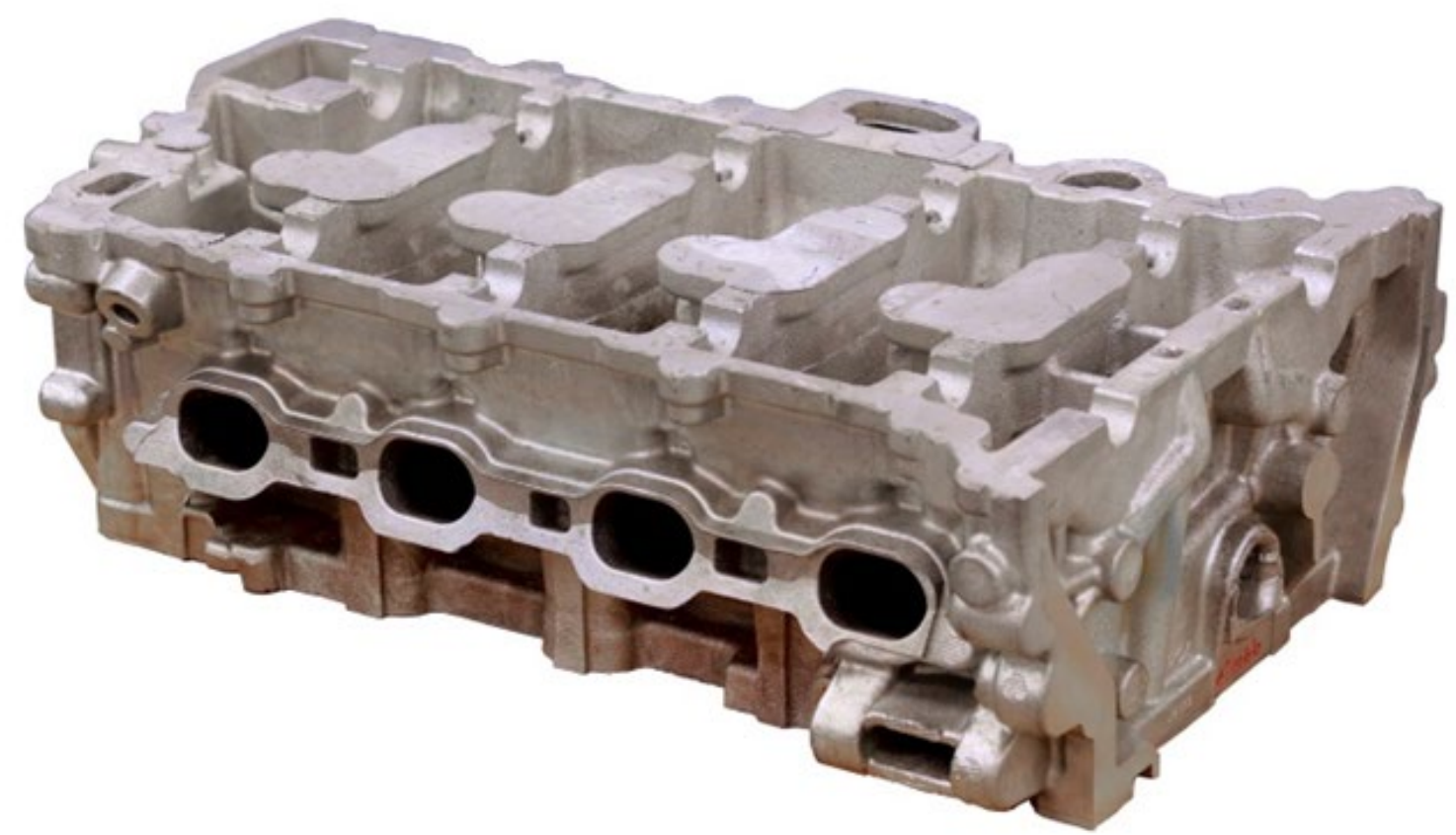

Figure 23: Cylinder head produced with the new aluminum alloy. 
Table 1: A list of facilities and tools that were utilized in the course of our four year effort.

\begin{tabular}{|c|c|}
\hline Facility/Tool Name & Context of Use \\
\hline Aberration Corrected Electron Microscope & $\begin{array}{l}\text { Look at precipitate microstructures, atomic scale imaging and } \\
\text { analysis }\end{array}$ \\
\hline $\begin{array}{c}\text { National Synchrotron Light Source (NSLS } \\
\text { at Brookehaven) }\end{array}$ & Phase identification in cast alloys \\
\hline Center for Nanophase Materials Science & Atom probe tomography \\
\hline $\begin{array}{l}\text { Mechanical, XRD, SEM, EPMA and thermal } \\
\text { property characterization }\end{array}$ & Characterization of baseline and new alloys at ORNL \\
\hline Spallation Neutron Source & Residual stress measurements on engine cylnder heads \\
\hline WPI Casting Facility & To determine the hot tearing resistance of new alloys \\
\hline ProCast & $\begin{array}{c}\text { Simulation of casting and thermal and mechanical properties of } \\
\text { baseline alloys (ORNL License) }\end{array}$ \\
\hline VASP & Density functional theory calculations (ORNL License) \\
\hline Element & $\begin{array}{c}\text { Constrained thermal fatigue testing and some of the ageing } \\
\text { dependent hardness studies }\end{array}$ \\
\hline SECO & Machinability studies on new alloys \\
\hline Nemak Casting Facility & $\begin{array}{l}\text { Larger scale castings and hot tear studies. Casting of tensile and } \\
\text { fatigue testing coupons and cylinder heads. }\end{array}$ \\
\hline ORNL Casting Facility & $\begin{array}{l}\text { Smaller scale castings for alloy development and hardness testing } \\
\text { coupon. }\end{array}$ \\
\hline FCA US Corrosion Evaluation & $\begin{array}{c}\text { Evaluation of baseline and new alloys in representative corrosive } \\
\text { environments }\end{array}$ \\
\hline FCA US Engine test Evaluation & Engine testing of components cast from new alloys \\
\hline
\end{tabular}

Table 1 provides a summary of the facilities used in the course of this CRADA project. In this project, over 120 cylinder heads were cast in multiple successful casting trials. Residual stress was measured with neutron diffraction techniques at an experiment performed at the Spallation Neutron Source (SNS) at ORNL in November 2016. The measurements were performed on cylinder heads cast with both the commercial diesel alloy $(\mathrm{A} 356+0.5 \mathrm{Cu})$ and one of our new alloys. The first stress invariant $(\mathrm{MPa})$ as a function of relative distance across the combustion cylinder face of a A356 + 0.5 Cu cylinder head was reported. More work was performed on characterizing the cylinder heads, developing appropriate heat treatments and characterization of machinability, thermal conductivity, corrosion resistance, thermomechanical fatigue resistance. Most of this work was led by the industry partners through their cost shared effort.

An engine test of one of our alloys to one lifetime was completed in December 2017. A preliminary cost model of our new cast aluminum alloy family was developed. A 7\% estimated increase in material costs for the new alloys was within the $10 \%$ total increase in cost that was stipulated in the original funding opportunity. Overall, this was a very successful collaborative effort between ORNL and the industry partners. A summary of the outcomes from this project in relation to the key FOA targets are summarized in Table 2.

Table 3 provides a summary of the project output. Our team received a 2017 R \& D 100 award for this alloy technology. A commercialization plan was outlined by FCA US and presented to DOE in the last quarter of the CRADA project. ORNL will also provide a Gap Analysis Report to DOE. 
Table 2: Outcomes of current project compared to targets in FOA.

\begin{tabular}{|c|c|c|}
\hline Property & Cast Alloy Targets & Outcomes \\
\hline Tensile Strength @ $300^{\circ} \mathrm{C}$ & 9.5 ksi @ 300C & $\begin{array}{c}19.8 \mathrm{ksi} @ 300^{\circ} \mathrm{C}(>2 \mathrm{X} \text { target and } \sim 3-4 \mathrm{X} \text { of baseline } \\
319 \text { and } 356 \text { type alloys })\end{array}$ \\
\hline $\begin{array}{l}\text { Hot Tearing Resistance and } \\
\text { Castability }\end{array}$ & Excellent & $\begin{array}{l}\text { Excellent (Improved hot tearing resistance compared } \\
\text { to } 319 \text { type alloys) }\end{array}$ \\
\hline Thermal Fatigue Performance & $50-300^{\circ} \mathrm{C}$ & $\begin{array}{l}5 X \text { compared to } A 356 \text { and } 2 X \text { compared to } 319 \text { type } \\
\text { alloys }\end{array}$ \\
\hline Cost & $\$ 1.1 \mathrm{x} / \mathrm{lb}$ & $\begin{array}{l}\text { Cost of alloys within } 10 \% \text { of baseline alloy cost } \\
\qquad(\sim 1.07 x)\end{array}$ \\
\hline Thermal Conductivity & No target in FOA & $\begin{array}{l}\text { Improved thermal conductivity compared to } 319 \\
\text { alloys and close to that of A356 + } 0.5 \mathrm{Cu} \text { alloy }\end{array}$ \\
\hline Machinability & No target in FOA & $\begin{array}{l}\text { Excellent and comparable to baseline alloys such as } \\
\qquad \mathrm{A} 356+0.5 \mathrm{Cu}\end{array}$ \\
\hline
\end{tabular}

Table 3: Summary of project output

\begin{tabular}{|c|c|}
\hline Activity & Outcome \\
\hline $\begin{array}{l}\text { Joint Patent } \\
\text { Applications }\end{array}$ & 3 \\
\hline Invention Disclosures & 4 \\
\hline Invited talks & 10 \\
\hline Publications & 10 \\
\hline Awards & $\begin{array}{l}\text { R\&D } 100 \text { Award 2017; ORNL Significant Event Award; December 2016; } \\
\text { Distinguished Researcher Award for team member Lawrence Allard; } 3^{\text {rd }} \text { Place - } \\
\text { Best Poster Award in TMS Annual Meeting; } 2^{\text {nd }} \text { Place - Best Poster Award, Oak } \\
\text { Ridge Chapter of ASM Students Poster Competition.. }\end{array}$ \\
\hline
\end{tabular}

\section{SUBJECT INVENTIONS (AS DEFINED IN THE CRADA)}

- $\quad$ A. Shyam, Y. Yamamoto, D. Shin, S. Roy, J. A. Haynes, P. Maziasz, A. Rodriguez, J. A. Gonzalez, J. Talamantes, L. Zhang and C. Glaspie, "Cast aluminum alloys with improved microstructural stability and strength at $350^{\circ} \mathrm{C}$ " ORNL Invention Disclosure Number 201503569, July 2015.

- $\quad$ A. Shyam, Y. Yamamoto, D. Shin, S. Roy, J. A. Haynes, P. Maziasz, A. Sabau, A. Rodriguez, J. A. Gonzalez, J. Talamantes, L. Zhang, S. Mirmiran and C. Glaspie, "Cast Aluminum Alloys having Improved Microstructural Stability and Strength at $350^{\circ} \mathrm{C}$ ” ORNL Invention Disclosure Number 201603642, February 2016.

- $\quad$ A. Shyam, Y. Yamamoto, D. Shin, S. Roy, J. A. Haynes, P. Maziasz, A. Sabau, A. Rodriguez, J. A. Gonzalez, J. Talamantes, L. Zhang, S. Mirmiran and C. Glaspie, "Aluminum alloy compositions and methods of making and using the same" US Patent Application Number 15/160,926, Filed May 20, 2016. 
- $\quad$ A. Shyam, Y. Yamamoto, D. Shin, J. A. Haynes, A. Sabau, A. Rodriguez, J. A. Gonzalez, S. Mirmiran and C. Glaspie, "Cast Aluminum Alloys Having Improved Hot Tearing Response" ORNL Invention Disclosure Number 201603804, November 2016.

- A. Shyam, Y. Yamamoto, D. Shin, J. A. Haynes, A. Sabau, A. Rodriguez, J. A. Gonzalez, S. Mirmiran and C. Glaspie, "Aluminum alloy compositions and methods of making and using the same” US Patent Application Number 15/594,434, Filed May 12, 2017.

- A. Shyam, J. A. Haynes, A. Rodriguez, J. A. Gonzalez, S. Mirmiran, C. Glaspie and G. Black, "Heat Treatments for High Temperature Cast Aluminum Alloys and Components Fabricated from Them" ORNL Invention Disclosure Number 201703963, August 2017.

- A. Shyam, J. A. Haynes, A. Rodriguez, J. A. Gonzalez, S. Mirmiran, C. Glaspie and G. Black, "Heat Treatments for High Temperature Cast Aluminum Alloys and Components Fabricated from Them" US Patent Application Number 62/577,324, Filed October 26, 2017.

\section{COMMERCIALIZATION POSSIBILITIES}

A formal commercialization plan for the alloys was developed and submitted to DOE.

The expected target market for ACMZ alloy is the automotive high-cylinder-pressure (\& temperature) gasoline engine cylinder head market as well as the diesel engine cylinder head market. Today, some of these engines cylinder heads use aluminum alloys at near the failure limit of the material. In both cases, a higher strength material would be beneficial.

The commercialization end state is when the requirements of TRL4 and TRL5 are met and the results are offered to the chief engineers within FCA US as a viable alternative. This is also accompanied by a commitment of the material foundry to fabricate the material. Timeframe to reach commercialization is 2-3 years after which the material should be available for adoption by a FCA US Chief Engineer, as a design element, to be incorporated into a production plan. The follow-on activities are extensive and proprietary to FCA US.

\section{PLANS FOR FUTURE COLLABORATION}

Informal collaborations and discussions will continue within the CRADA project team. Partnerships on future proposals including for engine block alloy development have been agreed by parties. The CRADA team plans to leverage this highly successful effort in future partnerships between ORNL and the automotive industry.

\section{CONCLUSIONS}

High temperature aluminum alloys called ACMZ alloys were developed by a team of researchers from ORNL with FCA US LLC and Nemak U.S.A. These new aluminum alloys are affordable, lightweight alloys capable of withstanding temperatures of almost $100^{\circ} \mathrm{C}$ more than current commercial alloys while providing exceptional thermomechanical performance and hot tear resistance. Common commercial alloys soften rapidly at high temperatures, limiting their use in next-generation vehicles, while other alloys that can withstand elevated temperatures are cost prohibitive and difficult to cast. ACMZ alloys were developed using a suite of atomic-level characterization and computation tools, resulting in a strong, stable and versatile material capable of withstanding the stressful conditions of next-generation high-efficiency combustion engines. The alloys have been engine tested at FCA US LLC and could be commercially available through our industry partners as early as 2019 . 


\section{Acknowledgements}

Research sponsored by the Propulsion Materials Program, DOE Office of Vehicle Technologies. Authors thank the following individuals for significant contributions to this research: Yukinori Yamamoto, Dongwon Shin, Shibayan Roy, Lawrence Allard, Adrian Sabau, Wallace Porter, Thomas Watkins, Dana McClurg, Shane Hawkins, Philip Maziasz, Ryan Cooper, Patrick Shower, Brian Milligan, Baishakhi Mazumder, Jonathan Poplawsky, James Morris (all of ORNL); Seyed Mirmiran, Chris Glaspie, Chris Capitan, Yi Liu, Lin Zhang (all of FCA US); Andres Rodriguez, Alejandro Gonzalez (all of Nemak). 
APPENDIX A. 



\title{
APPENDIX A. DISTRIBUTION LIST
}

\author{
Internal Distribution
}

Jeremy Busby

Craig Blue

Claus Daniel

Rich Davies

External Distribution

Jerry Gibbs (DOE)

Aaron Yocum (NETL) 